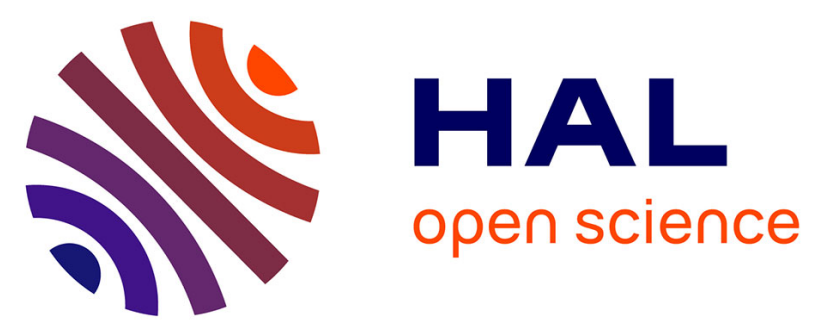

\title{
Characterisation and understanding of the corrosion behaviour of the nugget in a 2050 aluminium alloy Friction Stir Welding joint
}

Vincent Proton, Joël Alexis, Eric Andrieu, Jérôme Delfosse, Marie-Christine Lafont, Christine Blanc

\section{To cite this version:}

Vincent Proton, Joël Alexis, Eric Andrieu, Jérôme Delfosse, Marie-Christine Lafont, et al.. Characterisation and understanding of the corrosion behaviour of the nugget in a 2050 aluminium alloy Friction Stir Welding joint. Corrosion Science, 2013, vol. 73, pp. 130-142. 10.1016/j.corsci.2013.04.001 . hal-00932432

\section{HAL Id: hal-00932432 \\ https://hal.science/hal-00932432}

Submitted on 17 Jan 2014

HAL is a multi-disciplinary open access archive for the deposit and dissemination of scientific research documents, whether they are published or not. The documents may come from teaching and research institutions in France or abroad, or from public or private research centers.
L'archive ouverte pluridisciplinaire HAL, est destinée au dépôt et à la diffusion de documents scientifiques de niveau recherche, publiés ou non, émanant des établissements d'enseignement et de recherche français ou étrangers, des laboratoires publics ou privés. 


\section{Open Archive Toulouse Archive Ouverte (OATAO)}

OATAO is an open access repository that collects the work of Toulouse researchers and makes it freely available over the web where possible.

This is an author-deposited version published in: http://oatao.univ-toulouse.fr/ Eprints ID: 10598

To link to this article: DOI:10.1016/j.corsci.2013.04.001

http://dx.doi.org/10.1016/j.corsci.2013.04.001

\section{To cite this version:}

Proton, Vincent and Alexis, Joël and Andrieu, Eric and Delfosse, Jérôme and Lafont, Marie-Christine and Blanc, Christine Characterisation and understanding of the corrosion behaviour of the nugget in a 2050 aluminium alloy Friction Stir Welding joint. (2013) Corrosion Science, vol. 73. pp. 130-142. ISSN 0010-938X

Any correspondence concerning this service should be sent to the repository administrator: staff-oatao@listes-diff.inp-toulouse.fr 


\title{
Characterisation and understanding of the corrosion behaviour of the nugget in a 2050 aluminium alloy Friction Stir Welding joint
}

\author{
Vincent Proton $^{a}$, Joël Alexis ${ }^{b}$, Eric Andrieu ${ }^{a}$, Jérôme Delfosse ${ }^{c}$, Marie-Christine Lafont ${ }^{a}$, Christine Blanc ${ }^{\mathrm{a}, *}$ \\ ${ }^{a}$ Université de Toulouse, CIRIMAT, UPS/CNRS/INPT, 4 allée Emile Monso, BP 44362, 31030 Toulouse Cedex 04, France \\ ${ }^{\mathrm{b}}$ Université de Toulouse, LGP, ENIT/INPT, 47 av. d'Azereix, BP 1629, 65016 Tarbes Cedex, France \\ ${ }^{\mathrm{c}}$ EADS Innovation Works-IW/MS/MM, 12 rue Pasteur, BP 76, 92152 Suresnes Cedex, France
}

Keywords:

A. Aluminium

A. Alloy

B. Polarisation

B. TEM

C. Intergranular corrosion

C. Welding

\begin{abstract}
A B S T R A C T
The corrosion behaviour of the nugget of a Friction Stir Welding joint employing a $2050 \mathrm{Al}-\mathrm{Cu}-\mathrm{Li}$ alloy was investigated. The results showed that the nugget was susceptible to both intergranular and intragranular corrosion. Such corrosion behaviour was related to microstructural heterogeneities observed on a microscopic scale. Furthermore, heterogeneities in the corrosion behaviour of the nugget observed on a macroscopic scale were evidenced by a different corrosion behaviour from the top to the bottom of the nugget and by a localisation of the corrosion damage related to the "Onion ring structure". Critical microstructural parameters were identified to explain the results.
\end{abstract}

\section{Introduction}

The reduction in the weight of aircraft metallic structures is a current problem that the aeronautic industry has to address. At a time where the role played by composite materials is becoming more significant, the use of the Friction Stir Welding (FSW) process in combination with the new generation aluminium-copper-lithium alloy presents an alternative solution. The FSW process was developed by The Welding Institute (TWI) and consists of using a non-consumable, cylindrical, rotating tool (usually hardened steel) that moves over the seam of two butted plates and stirs them together [1]. Both a strong plastic deformation of the material and a strong increase in temperature were observed below the tool, while gradients of deformation and temperature were recorded perpendicularly to the joint, leading to gradients of microstructural evolution that were also perpendicular to the joint. Therefore, a typical FSW joint consists of the unaffected base material (BM), a heat affected zone (HAZ), a thermo-mechanically affected zone (TMAZ) and a dynamically recrystallised zone (nugget) as observed in Fig. 1 for a FSW joint of an Al-Cu-Li alloy 2050 studied in a previous work [2]. This alloy, i.e., the base material, is a precipitation hardening alloy. The main phase responsible for the hardening process is $T_{1}\left(\mathrm{Al}_{2} \mathrm{CuLi}\right)$, but some other precipitates should be found, including $\theta^{\prime}\left(\mathrm{Al}_{2} \mathrm{Cu}\right), T_{2}\left(\mathrm{Al}_{5} \mathrm{Li}_{3} \mathrm{Cu}\right)$ and $T_{B}\left(\mathrm{Al}_{7} \mathrm{Cu}_{4} \mathrm{Li}\right)$, which can also

\footnotetext{
* Corresponding author. Tel.: +33 (0)5 343234 07; fax: +33 (0)5 34323498 . E-mail address: christine.blanc@ensiacet.fr (C. Blanc).
}

contribute to strengthening the alloy but to a lesser extent than the $T_{1}$ precipitates [3-5]. Other intermetallic particles can be encountered in these alloys, such as $\mathrm{Al}_{3} \mathrm{Zr}$ particles, which prevent recrystallisation phenomena, and $\mathrm{Al}_{6} \mathrm{Mn}$ and $\mathrm{Al}_{20} \mathrm{Cu}_{2} \mathrm{Mn}_{3}$ particles, which help control the grain size [6]. The zones generated during the FSW process differ from one to another due to their grain size and morphology and because of their differences in hardening precipitation $[2,7,8]$. These microstructural differences lead to modification of the corrosion behaviour. For example, each zone of the FSW joint was characterised by its own corrosion potential value $[2,9,10]$, which led to galvanic coupling phenomena, as shown in a previous work [2]. The results obtained in this previous work showed that the nugget and the HAZ acted as sacrificial anodes when the welded joint was not heat treated after welding [2]. Conversely, a post-welding heat treatment inverted the corrosion potential values, shifting the potential of the BM toward more cathodic values so that it acted as a sacrificial anode. Other authors corroborated these results [11]. Nevertheless, the most interesting part of the FSW welded joint is the centre, called the nugget. Previous studies have revealed that the nugget has typical corrosion behaviour, closely linked to its particular microstructure that is generated by a combined role of high strain rate and temperature. Jariyaboon et al. [9] and Mahoney et al. [12] have measured the temperature in the centre of the weld, i.e., the nugget, and the authors found that it was approximately $481^{\circ} \mathrm{C}$ and $500{ }^{\circ} \mathrm{C}$, respectively. Moreover, Mahoney et al. [12] have also estimated that there was a gradient of temperature in the thickness of the joint and, 


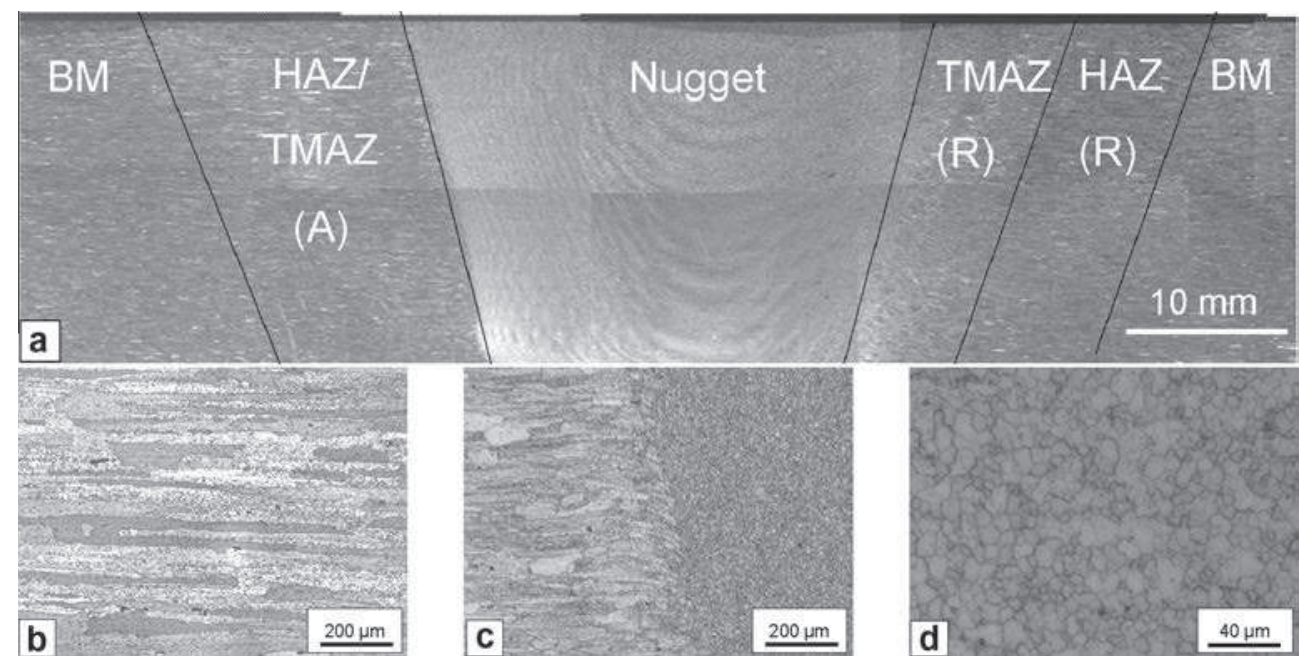

Fig. 1. Observations using an optical microscope of the FSW joint of AA 2050 alloy (Long Transverse-Short Transverse plane) submitted to a post-welding heat treatment (PWHT) after etching using the Keller reagent: (a) global view, (b) base metal zone, (c) HAZ zone in the retreating side and (d) nugget [2].

consequently, in the nugget. As mentioned before, the centre of the weld exhibits the most important deformation during the FSW process. Jata and Semiatin [13] have estimated a strain rate of $10 \mathrm{~s}^{-1}$, whereas Masaki et al. [14] assumed that it was approximately $2-3 \mathrm{~s}^{-1}$. It was assumed that the nugget was the place of dynamic recrystallisation and led to the formation of small equiaxed grains $[2,9,13,14]$. Some authors have noticed that the grain size was not homogeneous in the nugget $[15,16]$ and instead varied along the thickness of the joint, with a maximum grain size in the top of the nugget. This evolution could be attributed to the thermal gradient between the top and bottom caused by the presence of the shoulder. Fonda and Bingert [17] have also noticed the existence of a hardness variation between the top and bottom of the nugget and related the result to both a gradient of temperature and the reduction of time for $T_{1}$ precipitate nucleation in the bottom of the nugget. Moreover, the FSW process was found to lead to the formation of a typical microstructure called an "Onion Ring," which consists of bands of different textures, as observed in Fig. 1. Kumar and Kailas [18] proposed a mechanism to explain such a microstructure: a wrenching of the material in front of the tool while the material was then put behind the probe. Following this proposed mechanism, some authors found that the distance between two bands in the "Onion Ring" was equal to the distance reached by the probe in one evolution $[19,20]$. Microstructural heterogeneities at a finer scale were also found to have detrimental effects on the corrosion behaviour of the nugget. Birbilis and Buchheit [21] have studied the corrosion behaviour of intermetallic particles present in $\mathrm{Al}-\mathrm{Cu}-\mathrm{Li}$ alloys. They found that $\mathrm{Al}_{3} \mathrm{Zr}, \mathrm{Al}_{6-}$ $\mathrm{Mn}$, and $\mathrm{A}_{120} \mathrm{Cu}_{2} \mathrm{Mn}_{3}$ particles have a corrosion potential equal to $-0.752 \mathrm{~V} / \mathrm{SCE},-0.839 \mathrm{~V} / \mathrm{SCE}$ and $-0.550 \mathrm{~V} / \mathrm{SCE}$, respectively, in a $0.01 \mathrm{M} \mathrm{NaCl}$ solution whereas the matrix has a potential of $-0.679 \mathrm{~V} / \mathrm{SCE}$ in the same solution. Thus, some micro-galvanic coupling phenomena might appear to lead to the dissolution of the particles or the matrix. In addition, the hardening precipitates are very active particles, as mentioned by Li et al. [22], who evaluated the electrochemical behaviour of $T_{1}$ and $\theta^{\prime}$ with respect to the matrix and brought to light that the $\mathrm{T}_{1}$ precipitates had a more cathodic corrosion potential than the matrix in a $4 \% \mathrm{NaCl}$ solution. Li et al. [23] have also studied the evolution of the galvanic coupling between $T_{1}$ or $T_{2}$ precipitates with the matrix.

Therefore, numerous studies showed that the nugget of an aluminium alloy (AA) 2050 FSW joint presents a very heterogeneous microstructure, which suggests complex corrosion behaviour. In a previous study [2], the corrosion behaviour of an AA 2050 FSW joint has been studied, but the phenomena occurring in the nugget have not been elucidated. The aim of the present work is to investigate in detail the corrosion behaviour of the nugget of an AA 2050-T34 FSW joint and to correlate the results obtained to the microstructural characterisation to identify the critical microstructural parameters.

\section{Experimental procedures}

\subsection{Material}

The material studied in this work is a new generation aluminium-copper-lithium alloy AA 2050 (Al base, 3.5\% Cu, 1\% Li weight per cent) provided by Constellium (Voreppe, France). It consists of $15 \mathrm{~mm}$ thick-rolled plates of the T34 metallurgical state, which corresponds to stretching before natural ageing. Two plates were joined together by Friction Stir Welding (FSW) in the EADS Innovation Works Laboratory. The welding process consists of firmly bridling the two plates edge to edge. A rotating tool compounded by a probe and shoulder is plugged at the junction of the plates. Because of the friction phenomenon due to the rotation of the tool, the material is softened and can be deformed. The whole tool is then moved translationally along the frontier of the two plates to create the welded joint. The direction of welding is parallel to the rolling (longitudinal) direction of the plates. In this work, plates of $15 \mathrm{~mm}$ thickness were friction stir welded with a rotational speed of $400 \mathrm{rpm}$ and a welding speed of $200 \mathrm{~mm} / \mathrm{min}$. A threaded pin with three flats tool was used. After the welding process, some of the joints are submitted to a heat treatment, where the joint is maintained at $155^{\circ} \mathrm{C}$ for $30 \mathrm{~h}$. In the present work, when the nugget is studied as welded, without any post-welding heat treatment, the nugget is referred to as NHT (Not Heat Treated), whereas after the post-welding heat treatment, it is labelled PWHT (Post-Welding Heat Treatment).

\subsection{Corrosion tests}

The corrosion behaviour of the nugget was studied using conventional 3 day immersion tests and stationary electrochemical techniques. For the electrochemical measurements, a three-electrode electrochemical cell was used, including a platinum grid with a large surface area as the auxiliary electrode and a saturated calomel electrode (SCE) as the reference electrode. The FSW joint samples were used as the working electrode and, depending on 
the experiment, the surface exposed to the electrolyte corresponded to one of the three characteristic planes of the welded plates. Other experiments were also performed on nugget samples removed from the FSW joints. Before all corrosion tests, the sample surfaces were prepared with first an abrading procedure with 4000 grit $\mathrm{SiC}$ paper and then a polishing procedure using diamond paste down to $1 \mu \mathrm{m}$ and distilled water as the lubricant. All experiments were performed in a $0.7 \mathrm{M} \mathrm{NaCl}$ solution prepared by dissolving Normapur chemical salts in distilled water. Open circuit potential (OCP) measurements were performed with a test duration of approximately $2 \mathrm{~h}$. The OCP values given in this work correspond to average values calculated for the last $30 \mathrm{~min}$ of the test. Current-potential curves were also plotted; upon immersion of the sample in the electrolyte, the potential was immediately scanned at a rate of $500 \mathrm{mV} \mathrm{h}^{-1}$ from $-1100 \mathrm{mV} / \mathrm{SCE}$ to $-300 \mathrm{mV} / \mathrm{SCE}$. As a final test, a gel visualisation technique was used to study the global electrochemical behaviour of the welded joint [24]. The gel was obtained by mixing $3 \mathrm{~g}$ of Normapur agar agar powder in $100 \mathrm{~mL}$ of $0.7 \mathrm{M} \mathrm{NaCl}$ solution heated at $80^{\circ} \mathrm{C}$. Then, $15 \mathrm{~mL}$ of universal $\mathrm{pH}$ indicator were added, and the solution was laid on a cooled surface to obtain a 2-mm-thick film. Some parts of the film were cut and put on the surface of the welded joint, which had been polished as previously mentioned. The gel was maintained for $24 \mathrm{~h}$ on the FSW joint surface.

\subsection{Characterisation of the microstructure and observations of the corrosion features}

The microstructure of the nugget, in particular the grain size and grain orientation, was first revealed using electrochemical etching. The etching consisted of placing the material in a solution composed of $96.5 \mathrm{~mL}$ of distilled water and $3.5 \mathrm{~mL}$ of tetrafluoroboric acid. During the immersion, a $20 \mathrm{~V}$ potential was applied for $40 \mathrm{~s}$. The sample was immersed twice, with a $10 \mathrm{~s}$ emersion period in air between the two immersion steps. Then, the samples were observed using a PMG3 Olympus optical microscope. The microstructure of the nugget at a finer scale and, in particular, the precipitation state, was characterised using Transmission Electron Microscopy (TEM) observations from a JEOL-JEM-2010. The samples were obtained by removing $300 \mu \mathrm{m}$ thick slices from the nugget. The slices were ground down to approximately $100 \mu \mathrm{m}$ thick and a dimple was machined in the central region. Final electron transparency was obtained by ion milling on a precision ion polishing system (PIPS(tm), Gatan) using $5 \mathrm{kV} \mathrm{Ar}^{+}$ions. Characterisation of the nugget microstructure was completed by Electron Back Scattered Diffraction (EBSD) experiments performed on a JEOL 700F SEM-FEG equipped with the HKL Premium EBSD system Nordlys Fast. Before experiments, the samples were polished using differ- ent $\mathrm{SiC}$ papers and polishing sheets. A Castaing electronic microprobe (EPMA) was used for chemical analyses of the matrix. Experiments were performed on an SX50 CAMECA apparatus. Micro-hardness measurements were also performed to complete the microstructural characterisation of the samples by using a Zwick ZHU250 apparatus. Micro-hardness maps were obtained in the Long Transverse - Short Transverse plane of the joints; approximately 400 measurements using a Vickers tool were performed for each joint with a $200 \mathrm{~g}$ load. For additional characterisation, the PMG3 Olympus optical microscope was also used to observe the samples after the corrosion tests. In this case, the samples were removed from the electrolyte, rinsed with distilled water and then air-dried.

\section{Results: heterogeneities in the corrosion behaviour of NHT and PWHT nuggets}

Results obtained in a previous work showed that NHT and PWHT joints presented the same microstructure at the optical microscope scale with four different zones: base metal, HAZ, TMAZ and nugget [2]. These zones were found to have a different corrosion behaviour from one to another. In the present work, attention was paid to the corrosion behaviour of the nugget. Fig. 2 illustrates the results obtained from the gel visualisation technique after $24 \mathrm{~h}$ of exposure for the NHT (Fig. 2a and c) and PWHT (Fig. 2b and d) welded joints. The experiments were performed on the whole welded joint (long transverse - short transverse plane) but observations were focused on the nugget (Fig. 2c and d). Using this experimental technique, the electrochemical behaviour of each zone of the welded joint is given by the colour of the gel, due to the presence of the universal indicator. By considering Eqs. (1) and (2), an anodic reaction induces the apparition of an acidic area, characterised by a red/orange colour. On the contrary, Eq. (3) shows that a cathodic behaviour induces an alkaline $\mathrm{pH}$, characterised by a green colour.

$$
\begin{aligned}
& \mathrm{Al} \rightarrow \mathrm{Al}^{3+}+3 \mathrm{e}^{-} \\
& \mathrm{Al}^{3+}+\mathrm{H}_{2} \mathrm{O} \Longleftrightarrow \mathrm{AlOH}^{2+}+\mathrm{H}^{+} \\
& \mathrm{O}_{2}+2 \mathrm{H}_{2} \mathrm{O}+4 \mathrm{e}^{-} \rightarrow 4 \mathrm{OH}^{-}
\end{aligned}
$$

For the NHT joint, the BM presented a cathodic behaviour, whereas the HAZ and the nugget globally had an anodic behaviour. The post-welding heat treatment inverted the electrochemical behaviour so that, for the PWHT joints, the BM showed an anodic behaviour and the HAZ/nugget globally revealed a cathodic behaviour. As previously shown [2], the post-welding heat treatment led to a change in the electrochemical behaviour of the different zones

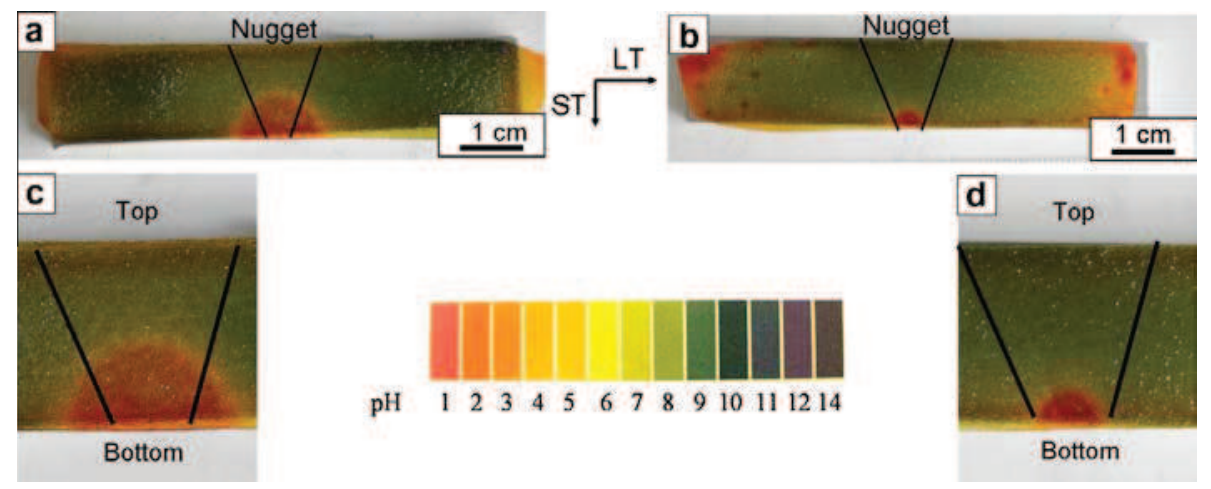

Fig. 2. Observations of the FSW joint of AA 2050 alloy after exposure to a visualisation gel: (a) NHT joint, global view; (b) PWHT joint, global view; (c) zoom on the nugget of the NHT joint; and (d) zoom on the nugget of the PWHT joint. 

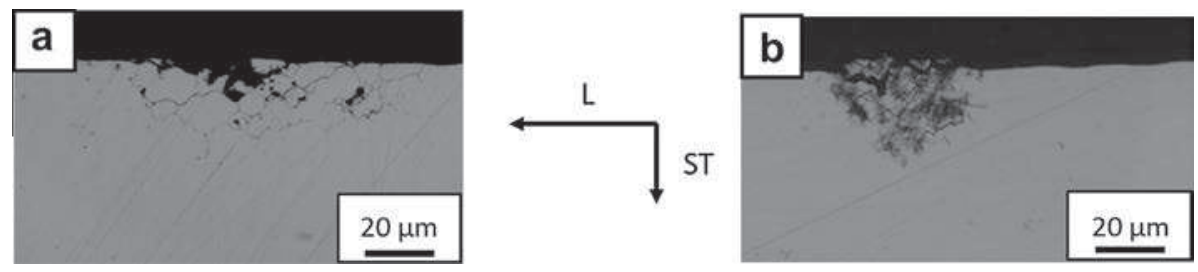

Fig. 3. Observations of the Longitudinal-Short Transverse plane for nugget samples after a 3 day immersion in a $0.7 \mathrm{M}$ NaCl solution: (a) NHT nugget and (b) PWHT nugget.

of the welded joints. Nevertheless, special attention was paid here to the electrochemical behaviour of the nugget. It was worth noticing that the bottom of the nugget presented a more anodic behaviour than the top of the nugget for both NHT and PWHT welded joints. Therefore, the results revealed a heterogeneous corrosion behaviour of the nugget at a mesoscopic scale independent of the metallurgical state of the nugget, i.e., for both NHT and PWHT nuggets. Moreover, even if the nugget globally presented a cathodic behaviour for the PWHT joint, corrosion features were observed in this nugget as well as in the NHT nugget, which globally had an anodic behaviour. Further experiments were then performed to study the corrosion damage for both nuggets. For all the following experiments, tests were performed on the nugget samples removed from the FSW joints to study the intrinsic corrosion behaviour of the nugget without galvanic coupling with the other zones of the welded joints. Similar tests were performed on the whole welded joints, and the results obtained also led to the previous conclusions concerning the corrosion morphology and the distribution of the corrosion defects for both nuggets. First, 3 day immersion tests in a $0.7 \mathrm{M} \mathrm{NaCl}$ solution were performed with the longitudinal L - Short Transverse ST surfaces of NHT and PWHT nuggets, respectively exposed to the electrolyte. Fig. 3 reveals that the nuggets are intrinsically susceptible to corrosion as suggested before by the results of the gel visualisation experiments. Indeed, gel visualisation results showed that, for the NHT joint, the nugget was globally the anodic site of the joint and obviously it was corroded. But, for PWHT joints, even if the nugget was globally a cathodic zone for the joint, corrosion features were observed in the nugget. The results obtained now with immersion tests performed on nugget samples removed from the joint before immersion confirmed the intrinsic susceptibility of the nuggets to corrosion. Fig. 3a shows that the NHT nugget is susceptible to intergranular corrosion whereas the PWHT nugget (Fig. $3 \mathrm{~b}$ ) is susceptible to both intergranular and intragranular corrosion. Moreover, corrosion features were found to be homogeneously distributed on the whole surface of the NHT nugget while, for the PWHT nugget, corrosion features were located in parallel bands. However, the corrosion was not highly extended to determine accurately the distribution of the corrosion damage. Therefore, samples removed from the two nuggets (NHT and PWHT) were submitted to a polarisation test in a $0.7 \mathrm{M} \mathrm{NaCl}$ solution. For these experiments, the Longitudinal L - Short Transverse ST surface was exposed to the electrolyte. These tests allowed to observe a more extended corrosion damage which made easier the localisation of the corrosion defects. Observations of the surface of the electrodes after the polarisation tests are summarised in Fig. 4; again, observations are focused on the NHT nugget (Fig. 4a) and PWHT nugget (Fig. 4b). First, the results were in good agreement with observations performed after a 3 day immersion test. The NHT nugget was homogeneously corroded (Fig. 4a) while, for the PWHT nugget, the corrosion features were localised in parallel bands (Fig. $4 \mathrm{~b}$ ). The corroded bands were oriented at $45^{\circ}$ and $90^{\circ}$ with respect to the welding direction. Their thickness was equal to $500 \mu \mathrm{m}$, the same as that of a non-corroded band. By moving from the beginning of a corroded band to the beginning of the following corroded band, a distance of approximately $1 \mathrm{~mm}$ was recorded. Therefore, for the PWHT nugget, another heterogeneity in the corrosion behaviour at a finer scale than before (i.e., differences between the top and bottom of the nugget) was demonstrated, with new corrosion damage mainly located in a few specific bands. Moreover, observations of the corrosion features confirmed that the two nuggets did not exhibit the same corrosion
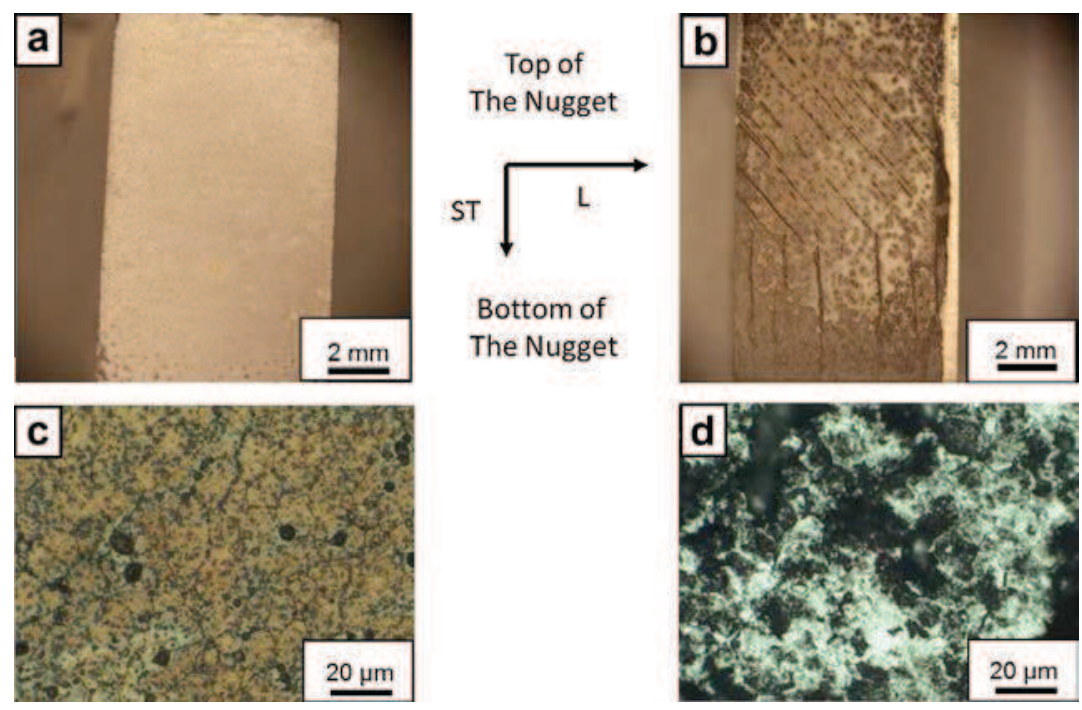

Fig. 4. Observations of the Longitudinal-Short Transverse plane for nugget samples after polarisation tests in a $0.7 \mathrm{M} \mathrm{NaCl}$ solution: (a and c) NHT nugget and (b and d) PWHT nugget. 
behaviour. The NHT nugget revealed a susceptibility to intergranular corrosion on its whole surface (Fig. 4c). On the contrary, for the PWHT nugget, a susceptibility to both intergranular and intragranular corrosion was revealed in the corroded bands (Fig. 4d).

\section{Discussion}

4.1. Understanding the susceptibility to intergranular and intragranular corrosion of the nuggets

As brought to light by the experiments performed, the morphology of the corrosion features observed in the corroded zones of the nuggets, i.e., in the whole surface of the NHT nugget and in some specific parallel bands for the PWHT nugget, depends on the metallurgical state of the nugget, with intergranular corrosion and both intergranular and intragranular corrosion observed for the NHT and PWHT nugget, respectively. TEM observations performed for the NHT nugget (Fig. 5) showed very few intragranular $T_{1}$ precipitates, displaying instead a dense intergranular precipitation where all the grain boundaries were decorated by fine precipitates (Fig. 5a). EDX analyses were carried out perpendicularly to a grain boundary (Fig. 5b) with the results reported in Table 1 . The intergranular precipitate analysed was found to contain more copper than the matrix around it, with an approximate chemical composition for the precipitate of $85 \mathrm{wt} . \% \mathrm{Al}$ and $15 \mathrm{wt} . \% \mathrm{Cu}$, whereas the matrix presented an approximate chemical composition of $97.5 \mathrm{wt} . \% \mathrm{Al}$ and $2.5 \mathrm{wt} . \% \mathrm{Cu}$. The chemical analysis combined with analyses of the crystallographic structure by using electronic diffraction (Fig. 5c) suggested that the intergranular precipitates could be attributed to the $\mathrm{Al}_{7} \mathrm{Cu}_{4} \mathrm{Li}\left(T_{B}\right)$ type. Chen and Bhat [25] also observed these precipitates in an $\mathrm{Al}-\mathrm{Li}-\mathrm{Cu}$ alloy, but at more elevated temperatures. In the present study, additional analyses performed on other intergranular precipitates led to the same results. However, due to the size of the precipitates, the chemical composition is not accurate, and these intergranular precipitates could also be attributed the $\theta^{\prime}$ type. Then, the difficulty is to explain the susceptibility of the NHT nugget to intergranular corrosion because the electrochemical behaviour of these two types of precipitates is different. The electrochemical behaviour of the $T_{B}$ phase
Table 1

EDX analyses performed on the TEM sample of the NHT nugget. The numbers (from 1 to 8 ) correspond to the points located in Fig. 5.

\begin{tabular}{|c|c|c|c|c|c|c|c|c|}
\hline & 1 & 2 & 3 & 4 & 5 & 6 & 7 & 8 \\
\hline at.\% Al & 85 & 85 & 97.8 & 97.5 & 97.6 & 96.7 & 97.5 & 97.5 \\
\hline at.\% Cu & 15 & 15 & 2.2 & 2.5 & 2.4 & 3.3 & 2.5 & 2.5 \\
\hline
\end{tabular}

was not studied in the literature, though that of the $T_{1}$ phase, which contains less copper, was studied by Li et al. [22]. $T_{1}$ precipitates were found to have a corrosion potential of $-1.076 \mathrm{~V} / \mathrm{SCE}$ in a $4 \% \mathrm{NaCl}$ solution, to be compared to a corrosion potential of $-0.855 \mathrm{~V} / \mathrm{SCE}$ for the matrix $\alpha$. If one assumed that the corrosion potential of $T_{B}$ precipitates is close to that of $T_{1}$ precipitates, some micro-galvanic coupling phenomena could occur between the matrix and the $T_{B}$ precipitates which would lead to the dissolution of $T_{B}$ particles and could explain the susceptibility to intergranular corrosion of the NHT nugget. Conversely, the $\theta^{\prime}$ phase presents a corrosion potential more anodic than that of the aluminium matrix [22]. Moreover, the chemical analysis performed perpendicular to the grain boundary did not allow for the determination of the presence of a depletion zone, or precipitate free zone (PFZ), close to the grain boundary. However, by analogy with what is observed in 2XXX aluminium alloys, it could be assumed there is galvanic coupling phenomena between the $\theta^{\prime}$ precipitates, the PFZ and the matrix, leading to the dissolution of the PFZ and, therefore, to a strong susceptibility to intergranular corrosion. TEM observations were also performed on the PWHT Nugget, with special attention paid to the precipitates present in the zone susceptible to corrosion. First, a nugget sample was removed from the PWHT joint, and half of the sample was protected by a varnish. The nugget sample was then polarised at a rate of $500 \mathrm{mV} \mathrm{h}^{-1}$ from $-1100 \mathrm{mV} / \mathrm{SCE}$ to $-300 \mathrm{mV} / \mathrm{SCE}$ in a $0.7 \mathrm{M} \mathrm{NaCl}$ solution. After polarisation, the varnish was removed, and a TEM sample was removed in a non-corroded zone in the prolongation of a corroded band. TEM observations revealed a dense precipitation of both intergranular and intragranular $T_{1}$ particles (Fig. 6). The formation of $T_{1}$ precipitates is not surprising when considering the work of Gable et al. [5] who have noticed that a heat treatment at $150{ }^{\circ} \mathrm{C}$ promotes the
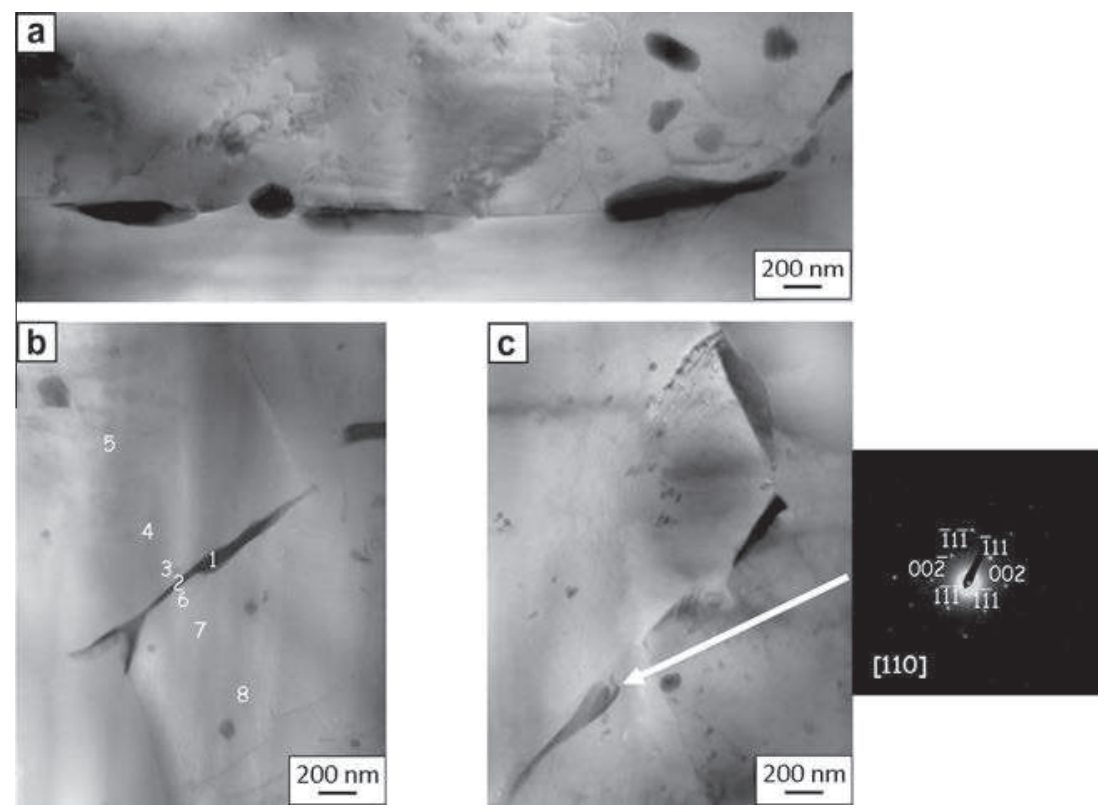

Fig. 5. TEM observations of the NHT nugget of the AA 2050 FSW joint: (a) a global view of a grain boundary and (b) intergranular precipitates. The number indicates points for EDX analyses. (c) Another intergranular precipitate and its corresponding diffraction pattern. 


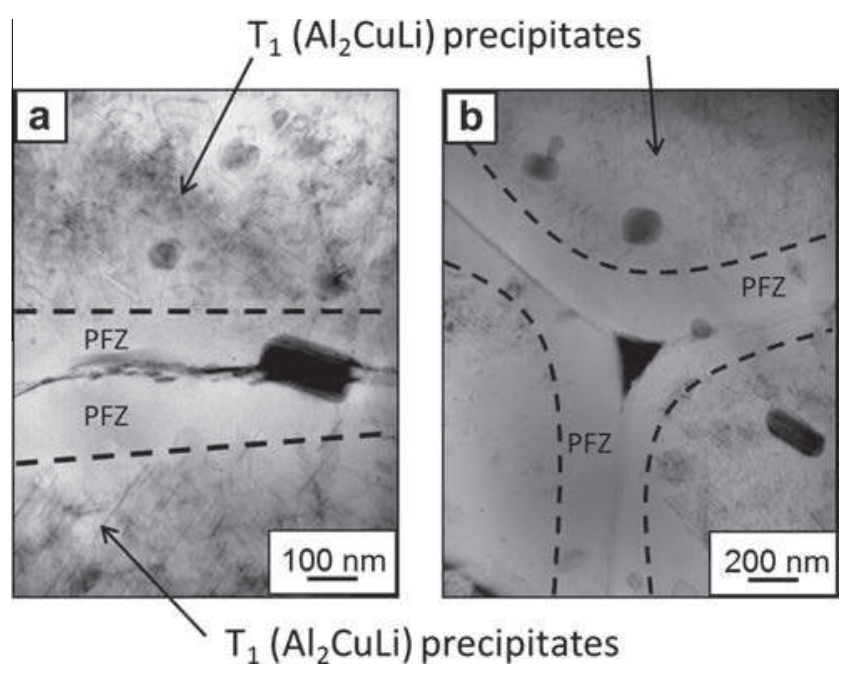

Fig. 6. TEM observations of the PWHT nugget of the AA 2050 FSW joint in the bands susceptible to be corroded: (a) intergranular precipitates and Precipitate Free Zone and (b) similar observations in another zone.

Table 2

Sum of the metallurgical parameters concerned with the corrosion behaviour of NHT and PWHT nuggets of the AA 2050 FSW joints.

\begin{tabular}{|c|c|c|c|}
\hline $\begin{array}{l}\text { Metallurgical } \\
\text { parameters }\end{array}$ & $\begin{array}{l}\text { Type of } \\
\text { heterogeneity }\end{array}$ & In the nugget & $\begin{array}{l}\text { Effect known } \\
\text { in the } \\
\text { literature }\end{array}$ \\
\hline Grain size & $\begin{array}{l}\text { Mesoscopic scale } \\
\text { (from the top to } \\
\text { the bottom) }\end{array}$ & $\begin{array}{l}\text { Yes in both } \\
\text { nuggets }\end{array}$ & {$[26,27]$} \\
\hline Onion rings/texture & $\begin{array}{l}\text { Mesoscopic scale } \\
\text { (period equal to } \\
500 \mu \mathrm{m} \text { ) }\end{array}$ & $\begin{array}{l}\text { Yes in both } \\
\text { nuggets }\end{array}$ & {$[19,20,28,29]$} \\
\hline Chemical composition & Mesoscopic scale & No data & {$[30,31]$} \\
\hline $\begin{array}{l}\text { Intergranular } \\
\text { precipitation }\end{array}$ & Microscopic scale & $\begin{array}{l}\text { Yes in both } \\
\text { nuggets }\end{array}$ & {$[22,23]$} \\
\hline $\begin{array}{l}\text { Intragranular } \\
\text { precipitation }\end{array}$ & Microscopic scale & $\begin{array}{l}\text { Yes but } \\
\text { mainly in the } \\
\text { PWHT nugget }\end{array}$ & \\
\hline
\end{tabular}

nucleation of $T_{1}$ precipitates at the expense of $\theta^{\prime}$ and $T_{B}$ particles. Moreover, in this study, a PFZ was observed all along the grain boundaries (Fig. 6a). As mentioned before, the corrosion potential of $T_{1}$ precipitates is more cathodic compared to that of the matrix in a $\mathrm{NaCl}$ solution, which could induce some galvanic coupling phenomena, leading to the dissolution of the $T_{1}$ precipitates present in the grain boundaries and in the grains. Moreover, the galvanic coupling phenomena had to be extended to the PFZ that contains less copper than the matrix and $T_{1}$ precipitates. Therefore, both intergranular $T_{1}$ precipitates and the PFZ had to be considered as critical metallurgical parameters to explain the PWHT nugget's susceptibility to intergranular corrosion. Concerning the nugget's susceptibility to intragranular corrosion, it seems relevant to refer to intragranular $T_{1}$ precipitates that are homogeneously distributed in the grain (except in the PFZ) as their dissolution due to microgalvanic coupling with the matrix could lead to grain dissolution. Moreover, it could also be assumed that the formation in the grain of numerous $T_{1}$ precipitates could lead to a decrease in the copper content of the aluminium solid solution. Therefore, the matrix itself is less resistant to corrosion, which could contribute to the PWHT nugget's susceptibility to intragranular corrosion.

Therefore, the results showed that both intergranular and intragranular precipitates constitute critical metallurgical parameters to explain the susceptibility to corrosion of the nugget for the AA 2050 FSW joints, whatever their metallurgical state. Some comments about the distribution of these precipitates, with the presence of a PFZ, as well as about the chemical composition of the aluminium solid solution were also given to explain the susceptibility to both intergranular and intragranular corrosion of the PWHT nugget. However, additional data are needed to explain the heterogeneities observed in the corrosion behaviour of both nuggets, i.e., heterogeneities such as a different corrosion behaviour between the top and bottom of the nugget for both nuggets and the localisation of the corrosion features in some specific bands for the PWHT nugget. Indeed, it seems relevant to assume that other metallurgical factors could be helpful in explaining such corrosion behaviour, e.g., the grain size, the texture or the chemical composition of the matrix. Table 2 sumps up these metallurgical parameters and indicates some published works in which the influence of one of these metallurgical parameters on the corrosion behaviour of a material was studied. Further experiments and observations were therefore performed to identify the other critical metallurgical parameters for the corrosion behaviour of the nuggets of AA 2050 FSW joints.

\subsection{Heterogeneities in corrosion behaviour between the top and bottom of the nugget}

First, the discussion was focused on the heterogeneities observed in the corrosion behaviour between the top and bottom of the nugget (Fig. 2). Fig. 7 shows the OCP measurements performed in the thickness of both the NHT and PWHT nuggets. OCP measurements were performed in the L-LT plane beginning on the top of the nugget to its bottom. A set of OCP measurements was obtained by progressively polishing the nugget. After each polishing step equal to $1.3 \mathrm{~mm}$, an OCP measurement was performed. Fig. 7a compares the grain size variation and the variation of the OCP values throughout the thickness of the NHT nugget. The OCP values decrease through the thickness of the nugget, with an average value of $-0.635 \mathrm{~V} / \mathrm{SCE}$ near the top of the nugget and a minimum value of $-0.665 \mathrm{~V} / \mathrm{SCE}$ at the bottom of the nugget. This was not a linear evolution, with an important drop in the OCP values observed for the last $4-5 \mathrm{~mm}$ from the bottom surface. These measurements were in good agreement with the results obtained with the gel visualisation technique (Fig. 2). Indeed, the zone presenting the most cathodic potential, i.e., the most anodic behaviour, was located in the last $4-5 \mathrm{~mm}$, which corresponded to the size of the orange spot in Fig. 2c. Therefore, the results showed that even if the nugget globally acted as a sacrificial anode in the NHT joint, local galvanic coupling phenomena occurred between the top and bottom of the nugget. Comparison of both the OCP and grain size variations in the thickness of the NHT nugget showed that the OCP values decreased when the grain size decreased, which suggested that the grain size could be helpful in explaining the difference in electrochemical behaviour between the top and bottom of the nugget. Similar results were obtained for the PWHT nugget (Fig. 7b). The OCP values were found to decrease from $-0.700 \mathrm{~V} / \mathrm{SCE}$ at few millimetres under the top surface to $-0.726 \mathrm{~V} / \mathrm{SCE}$ when approaching the bottom surface. An important drop in the OCP values was observed at 1-2 $\mathrm{mm}$ from the bottom surface, which corresponded to the small orange spot observed previously (Fig. 2d). For the PWHT nugget, a good correlation was observed between both OCP and grain size variations suggesting once more that the grain size could be a critical parameter for explaining the corrosion behaviour of the nugget of the AA 2050 FSW joint. Numerous works in literature showed that it was not unreasonable to expect fine grained alloys to exhibit different electrochemical behaviour than coarse grained alloys. A relationship between grain size and corrosion rate has yet been identified for 


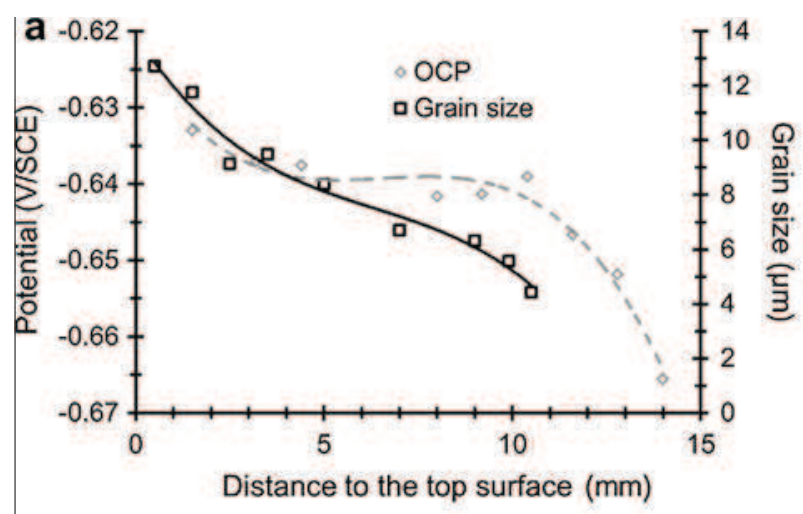

C

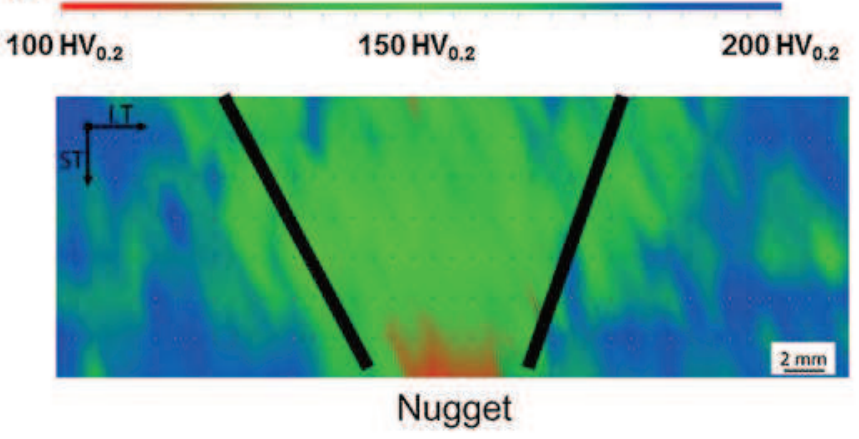

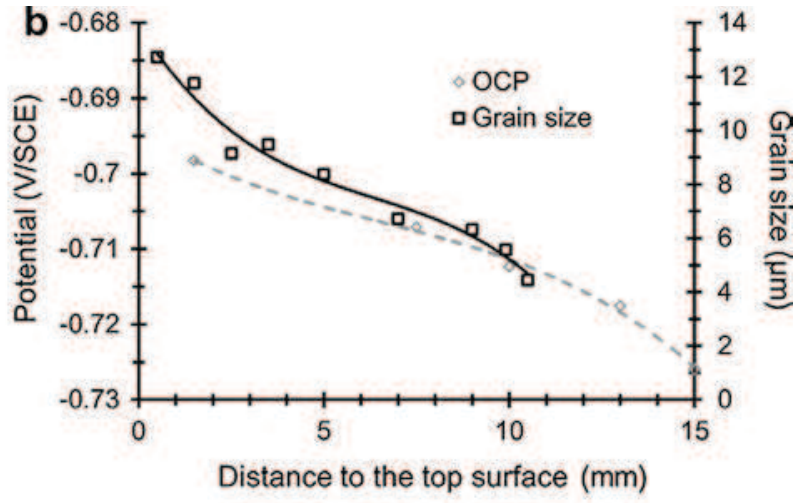

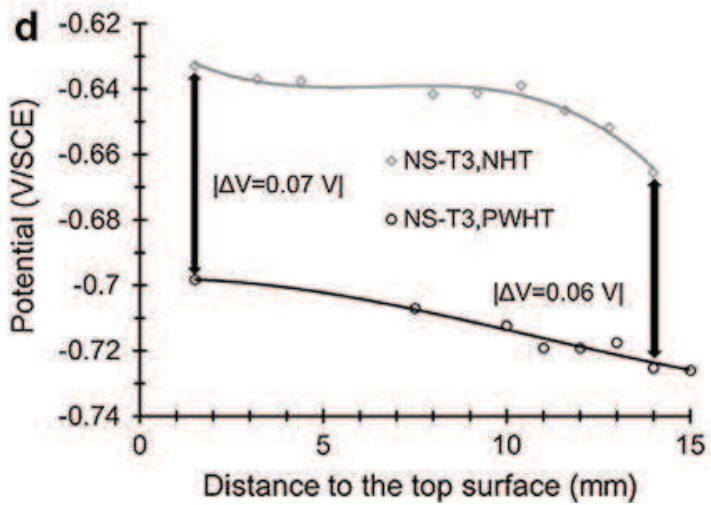

Fig. 7. (a) Variation of the Open Circuit Potential measured in a $0.7 \mathrm{M} \mathrm{NaCl}$ solution and of the grain size from the top to the bottom for the NHT nugget; (b) similar results for the PWHT nugget; (c) micro-hardness map obtained on a PWHT joint; and (d) comparison of the results obtained for NHT and PWHT nuggets.

steels [26] but also for pure aluminium or aluminium alloys [27,32-34]. Zhao et al. proposed a generalised model for intergranular corrosion growth in aluminium alloys and showed that the intergranular corrosion rate was highly related to grain size and shape [35]. The majority of the studies that consider grain size and pure aluminium or aluminium alloys suggest that as grain size decreases corrosion resistance improves [27,32,33]. For example, Ralston et al. showed that decreasing grain size resulted in an ennoblement of the corrosion potential [27]. However, fine grained aluminium has also been found to be less corrosion resistant than coarse grained aluminium [36]. The results obtained in the present study seemed to show that a finer grained nugget exhibited a more cathodic corrosion potential than a coarse grained nugget which was in agreement with Mahmoud's work [36] but contradictory to the other works cited above. The susceptibility to corrosion observed for finer grained alloys could be related to an increased grain boundary density that will likely enhance overall surface reactivity. However, as explained by Ralston et al. [27], determining a definitive 'grain size-corrosion resistance' relationship is inherently complex as the evolution of the grain size always imparts other changes to the microstructure, for example the development of texture, internal stresses and segregation of alloying elements to grain boundaries. Authors showed a strong correlation of intergranular attack around grains with higher grain stored energy [37] and others evidenced that grain boundary character distribution had a great effect on intergranular corrosion susceptibility of aluminium [38]. In the present work, all the parameters cited above could be considered as relevant parameters. Among them, the distribution of alloying elements is a parameter worthy of additional comments. Geuser et al. performed Small Angle X-ray Scattering analyses (SAXS) for a nugget from an AA 2050 FSW joint obtained by welding two rolled plates in a T34 metallurgical state then ageing at $155^{\circ} \mathrm{C}$ [39]. The SAXS mapping obtained for this nugget showed that there was a gradient of precipitation ( $T_{1}$ and $\theta^{\prime}$ precipitates) between the top and bottom of the nugget with a larger density of $T_{1}$ precipitates in the top region of the nugget. Similar results might be expected for the nuggets studied in this work. Fig. 7c shows a micro-hardness map obtained for the PWHT nugget; a similar map was obtained for the NHT nugget. A gradient of micro-hardness was observed from the top to the bottom of the nugget, in agreement with the gradient of $T_{1}$ precipitate density. Taking into account the electrochemical behaviour of the $T_{1}$ phase compared to that of the matrix, it could be assumed that a greater density of $T_{1}$ precipitates in the top than in the bottom of the NHT and PWHT nuggets should induce a more cathodic potential, i.e. a more anodic behaviour, in the top than in the bottom. Furthermore, a strong density of $T_{1}$ precipitates in the top of the nuggets will lead to an impoverishment in copper for the solid solution, which could contribute to the shift of the corrosion potential in the top toward more cathodic values. Obviously, this explanation is not in agreement with the corrosion behaviour observed. Nevertheless, the role of both intergranular and intragranular $T_{1}$ precipitates should not be neglected. These precipitates explain the susceptibility of the nugget to both intergranular and intragranular corrosion, as shown before. Moreover, a comparison of the OCP variations recorded for both nuggets (Fig. 7d) suggested that the fine precipitates played a role in explaining the heterogeneities between the top and bottom of the nugget. Indeed, results showed first that anywhere in the PWHT nugget, the OCP value was more cathodic than in the NHT nugget, which supports the observation of a strong density of intragranular $T_{1}$ precipitates in the PWHT nugget. Moreover, the difference in OCP values between the two nuggets was closely linked to the density of the $T_{1}$ precipitates because, although the two OCP curves had the same shape, 

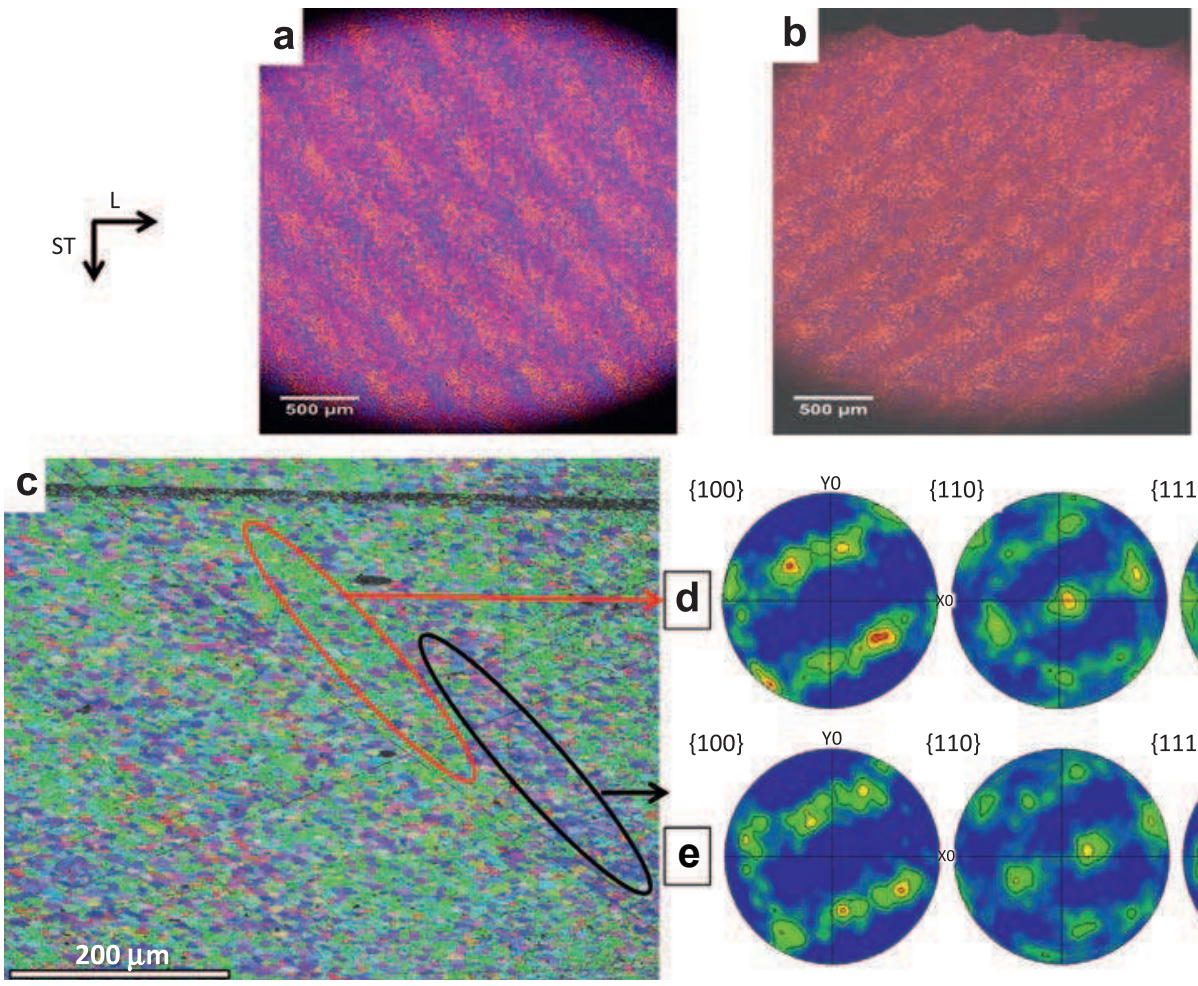

$\{111\}$

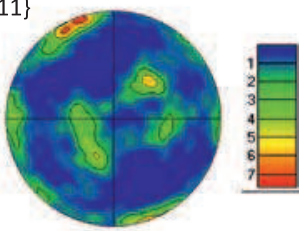

$\{111\}$

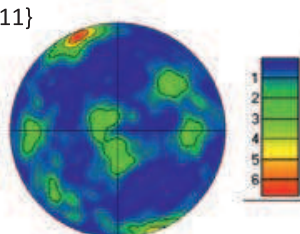

Fig. 8. Observations using an optical microscope of the nugget of an AA 2050 FSW joint after electrochemical etching: (a) NHT nugget; (b) PWHT nugget; (c) EBSD analyses performed on the PWHT nugget; ( $d$ and e) pole figures corresponding to bands of different textures.

they were not parallel. At $1.5 \mathrm{~mm}$ from the top, the difference in OCP values between the two nuggets was equal to $0.07 \mathrm{~V}$ (absolute value), whereas it was only approximately $0.06 \mathrm{~V}$ at $1 \mathrm{~mm}$ from the bottom surface. Therefore, the difference in OCP values was maximal in the top when there were more $T_{1}$ precipitates. Of course, the values $0.07 \mathrm{~V}$ and $0.06 \mathrm{~V}$ are very close, but one can assume that the precipitation was helpful in explaining the heterogeneities in the corrosion behaviour between the top and bottom of the nugget. Therefore, the results obtained here evidenced a relationship between the grain size of the nugget and its electrochemical behaviour. A finer grained nugget was characterised by a more cathodic corrosion potential. This could lead to assume that as the grain size decreases, for this alloy, the corrosion potential decreases. Comparison of the corrosion potential measured for the NHT nugget and that of the NHT base metal, characterised by a coarser grained microstructure, could confirm this assumption as the corrosion potential of the NHT base metal $(-0.615 \mathrm{~V} / \mathrm{SCE})$ was more anodic than that of the NHT nugget. However, opposing results were obtained for the PWHT samples: the corrosion potential of the base metal, with coarser grains, was more cathodic than that of the nugget. But, interpretation of the results was complicated since the post welding heat treatment induced modifications of the alloying elements distribution. Therefore, this work evidenced a relationship between the grain size and the electrochemical behaviour of the nugget but it was not possible, with the data, to conclude since other parameters could influence the results.

\subsection{On the origins of the localisation of corrosion features in parallel bands for PWHT nugget}

For the PWHT nugget, as previously shown, the corrosion features were located in parallel bands. This specific localisation of the corrosion damage seems to be closely linked with a typical microstructure observed in Friction Stir Welding joints that is called "Onion Rings". The onion rings microstructure is known to result from the high strain rate and the elevated temperature in the centre of the welded joint $[19,20]$. In the present study, an electrochemical etching with tetrafluoroboric acid in the L-ST planes of both nuggets allowed the microstructure of the nuggets to be revealed and, thanks to the different colours observed, the differences in grain orientations to be more precisely established. Fig. 8a and b shows that, at this scale, both nuggets presented the same microstructure composed of two types of parallel bands with seemingly different crystallographic orientations. The distance between two bands characterised by the same crystallographic orientation was equal to $500 \mu \mathrm{m}$, which corresponded to the distance covered by the probe in one rotation. Inside each $500 \mu \mathrm{m}$ width band, three sub-bands were observed (orange, magenta and blue colours ${ }^{1}$ in Fig. $8 \mathrm{a}$ and $\mathrm{b}$ ). The sub-bands were correlated to the geometry of the welding tool; indeed, a threaded pin with three flats tool was used. Additional EBSD analyses allowed this strong texture to be confirmed. Fig. 8c shows an EBSD map obtained in the L-ST plane of the middle of the PWHT nugget (from the top to the bottom) in which two types of parallel bands were shown. The corresponding pole figures (Fig. 8d and e) confirmed that each type of band was characterised by a particular crystallographic orientation. The two types of bands seemed to be distinguished by the level of disorientation of the (110) planes compared to the ST direction of the welded plate. The same EBSD results were obtained for the NHT nugget. This strong texture was strongly suggestive of the specific localisation of the corrosion damage for the PWHT nugget. To confirm the link between the corrosion localisation and the texture observed, a particular experimental procedure was used. The lower part of the L-ST plane of a PWHT nugget sample removed from the joint was covered with a varnish (visible in Fig. 9a). The sample was then immersed in a $0.7 \mathrm{M} \mathrm{NaCl}$ solution and polarised from $-1100 \mathrm{mV} / \mathrm{SCE}$ to $-300 \mathrm{mV} / \mathrm{SCE}$ so that corrosion damage developed

${ }^{1}$ For interpretation of color in Fig. 8, the reader is referred to the web version of this article. 

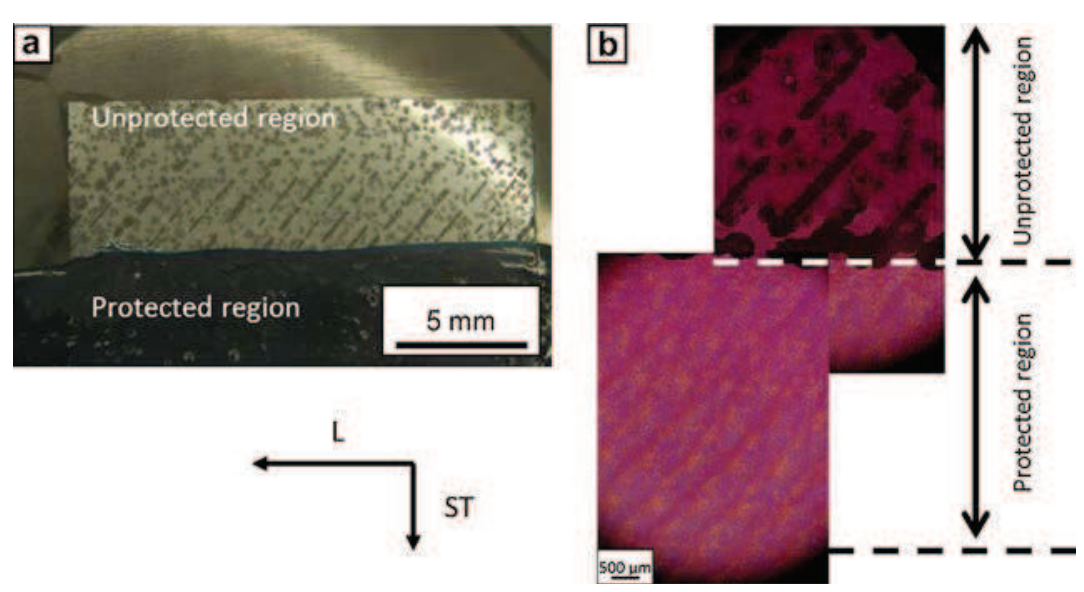

Fig. 9. Observations of the Longitudinal-Short Transverse plane for a PWHT nugget sample after polarisation tests in a $0.7 \mathrm{M}$ NaCl solution: (a) before electrochemical etching and (b) after electrochemical etching. The bottom of the sample was covered by a varnish during the corrosion test.

on the unprotected part of the sample (Fig. 9a). After the polarisation test, the varnish was removed and an electrochemical etching with tetrafluoroboric acid was performed. The L-ST plane of the half-corroded sample after etching was observed in polarised light (Fig. 9b). In Fig. 9b, the corrosion damage is observed on the top of the figure while the bottom of the sample was protected by the varnish and so did not display any corrosion damage. The electrochemical etching allowed one to show that the bands where the corrosion damage was located are directly superimposable with one type of bands characterised by a specific crystallographic orientation. Therefore, the results evidenced a correlation between the localisation of the corrosion damage of the PWHT nugget and its texture.

Nevertheless, the texture observed cannot be the key factor responsible for the localisation of the corrosion damage in the PWHT nugget. Indeed, as shown in Fig. 8a and b, both NHT and PWHT nuggets presented the same texture with two types of par- allel bands but only the PWHT nugget evidenced a localisation of the corrosion damage. One can assume, as suggested in Table 2, that the grain size could be a critical metallurgical parameter in this case. Using EBSD analyses, the grain size in the two types of parallel bands was measured, of course at the same level in the nugget to take into account the results from Fig. 7. No significant difference in grain size was observed from one band to the other. It is also known that the chemical composition is a key parameter in the corrosion behaviour of materials (Table 2). Concerning the present study, assuming a difference of chemical composition from one type of band to another seemed to not be relevant. Indeed, the main advantage of the FSW process is that there is no transition in a liquid state during the welding, so variations of chemical composition in the nugget are not expected. Nevertheless, to set aside this factor, some chemicals measurements were performed in the L-ST plane of the PWHT nugget using an EPMA system. This allowed
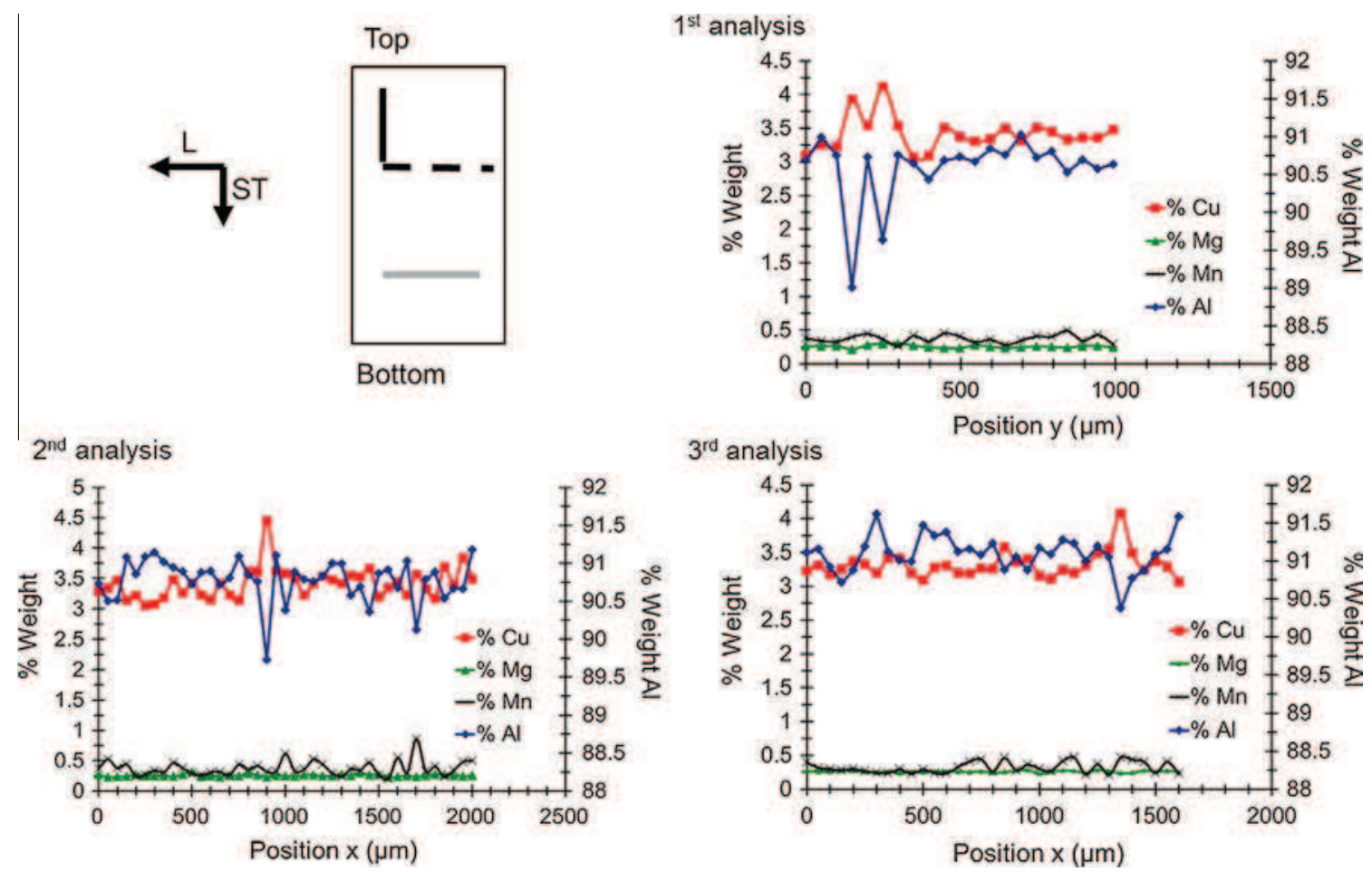

Fig. 10. EPMA analyses performed for a PWHT nugget of AA 2050 FSW joint. 

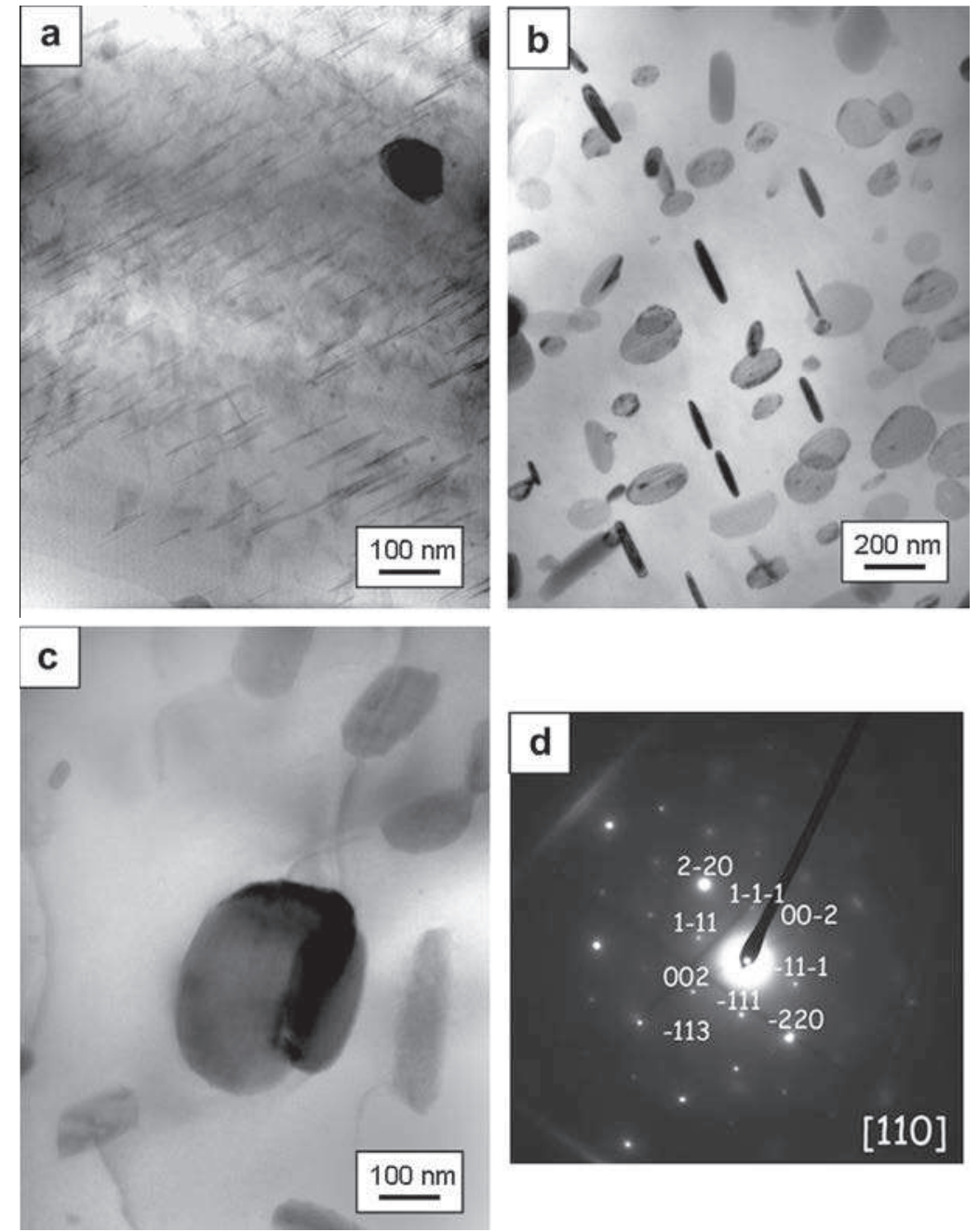

Fig. 11. TEM observations performed for the PWHT nugget of AA 2050 FSW joint: (a) slices removed in parallel bands susceptible to be corroded; (b) slices removed in parallel bands that did not corrode in a $\mathrm{NaCl}$ solution; (c) zoom on a precipitate from the bands that did not corrode in a NaCl solution; (d) electron diffraction pattern for the precipitate observed in (c).
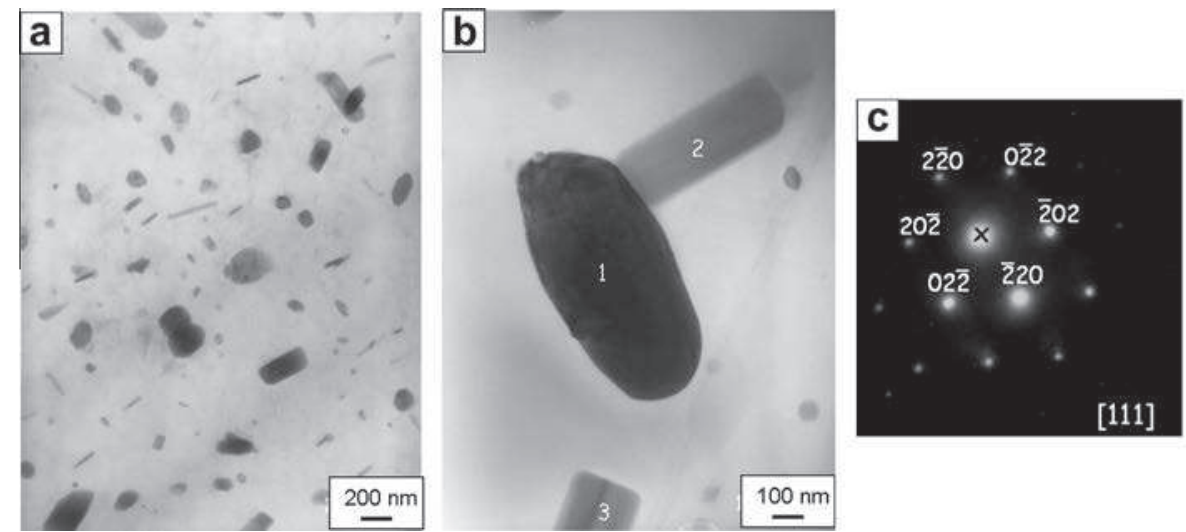

Fig. 12. TEM observations for the NHT nugget of AA 2050 FSW joint submitted to a heat treatment at $430{ }^{\circ} \mathrm{C}$ for $15 \mathrm{~h}$ : (a) global view; (b) zoom on a precipitate; (c) corresponding diffraction pattern.

quantitative measurements of the chemical composition in the different types of parallel bands to be obtained. To bring to light a potential periodic variation of chemical composition due to these bands, measurements were performed every $50 \mu \mathrm{m}$ on a $2 \mu \mathrm{m} \times 2 \mu \mathrm{m}$ surface and at a distance at least equal to $1 \mathrm{~mm}$ along the $\mathrm{L}$ and ST directions. As the width of the smallest sub-band is equal to $100 \mu \mathrm{m}$, this procedure is ensured to obtain an analysis of the two types of parallel bands. The results are summarised in Fig. 10. The black line symbolises a first analysis performed in the top of the nugget. Some fluctuations of the chemical 


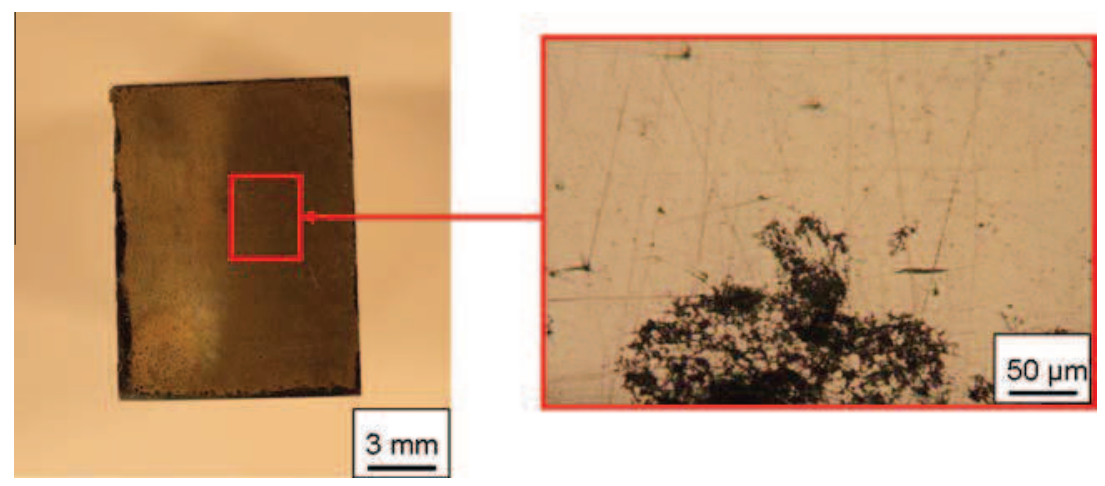

Fig. 13. Observations of the NHT nugget of AA $2050 \mathrm{FSW}$ joint submitted to a heat treatment at $430{ }^{\circ} \mathrm{C}$ for $15 \mathrm{~h}$ after polarisation tests in a $0.7 \mathrm{M}$ NaCl solution.
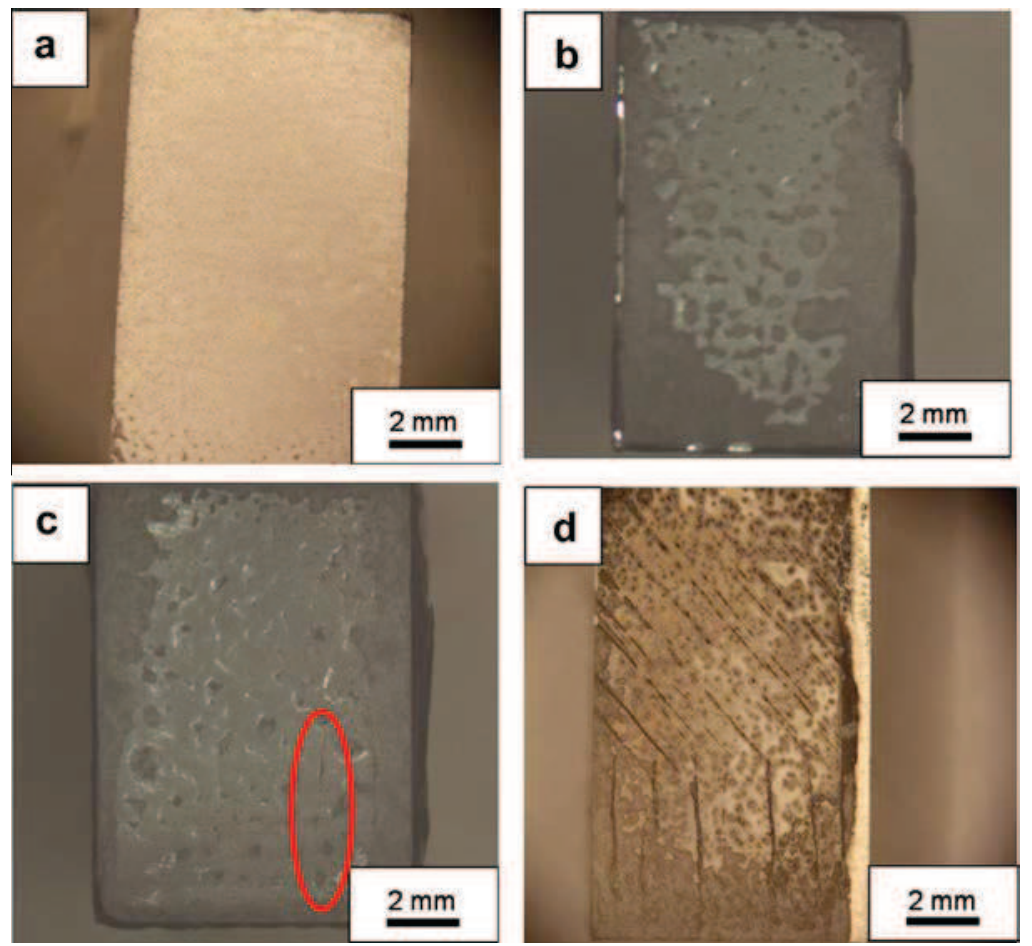

Fig. 14. Observations of the NHT nugget of AA $2050 \mathrm{FSW}$ joint after polarisation tests in a $0.7 \mathrm{M} \mathrm{NaCl}$ solution. Before corrosion tests, the nugget samples were submitted to a heat treatment at $150{ }^{\circ} \mathrm{C}$ for (a) $0 \mathrm{~h}$ (NHT); (b) $5 \mathrm{~h}$; (c) $9 \mathrm{~h}$; and (d) duration time longer than $9 \mathrm{~h}$ (PWHT). In figure (c), the red oval shape evidences the localisation of the corrosion damage. (For interpretation of the references to colour in this figure legend, the reader is referred to the web version of this article.)

composition were observed, but were determined to not be meaningful. Similar measurements were performed along the black dotted line and the grey line at distances of $2 \mathrm{~mm}$ and $1.5 \mathrm{~mm}$, respectively. Similarly, these measurements did not highlight any periodic variations in chemical composition.

Based on the results, it was assumed that the localisation of the corrosion features in some of the parallel bands for the PWHT nugget could be related to the precipitation state. One could think about a difference in the density of fine precipitates from one type of band to another or about the presence of different types of precipitates in one band versus another. For further understanding, TEM slices were removed in the L-ST plane of the PWHT nugget. Some were removed in a band susceptible to corrosion upon immersion in a $\mathrm{NaCl}$ solution, and other slices were removed in a band that did not corrode upon immersion. To be successful in this TEM slice preparation, the two types of bands were located as previously explained. Fig. 11 evidenced that the morphology of the precipitates present in the two slices are completely different. In slice 1 (Fig. 11a), which corresponded to the bands susceptible to corrosion, numerous $T_{1}$ precipitates were observed in the grains and in the grain boundaries as previously shown in Fig. 6 . In the other slice (Fig. 11b and c), the precipitates observed both in grains and grain boundaries revealed a cylindrical shape with a radius of approximately $200 \mathrm{~nm}$ for $50 \mathrm{~nm}$ of thickness. Observations of the precipitates were repeated many times by tilting the slice in the TEM to observe the sample in various directions. All observations confirmed that the precipitates present in the bands that did not corrode in the PWHT nugget had a different morphology than those observed in the other types of parallel bands. Electronic diffraction analyses (Fig. 11d) showed that these precipitates could be attributed a $\mathrm{T}_{\mathrm{B}}\left(\mathrm{Al}_{7} \mathrm{Cu}_{4} \mathrm{Li}\right)$ type of precipitate. Therefore, it was reasonable to explain the localisation of the corrosion damage in PWHT nugget by referring to the precipitation state, i.e., to the fact that the precipitates present in the two types of parallel bands were different. To assess this hypothesis, a "modified" PWHT nugget sample was synthesised by submitting a NHT nugget to a 
modified post-welding heat treatment to promote the precipitation of $T_{B}$ precipitates in the whole nugget. The temperature and the duration of this heat treatment were fixed according to the time-temperature-precipitation diagram proposed by Chen and Bhat [25] for the aluminium-copper-lithium alloy 2195, whose chemical composition is close to that of the 2050 alloy. The heat treatment consisted of maintaining the NHT nugget at $430{ }^{\circ} \mathrm{C}$ for $15 \mathrm{~h}$. TEM observations performed on numerous slices removed from this sample (Fig. 12) combined with electronic diffraction studies confirmed that the large part of the precipitates present in the "modified" PWHT nugget were $T_{B}\left(\mathrm{Al}_{7} \mathrm{Cu}_{4} \mathrm{Li}\right)$ particles, even though a few $\theta^{\prime}$ and $\theta^{\prime \prime}$ precipitates were observed. The "modified" PWHT nugget was then submitted to a polarisation test, with the L-ST plane exposed to a $0.7 \mathrm{M} \mathrm{NaCl}$ solution. Observations of the sample after this corrosion test (Fig. 13) showed that the corrosion damage was located on the whole surface of the nugget. Therefore, the results showed that the 2050 alloy with $T_{B}$ precipitates is susceptible to intergranular corrosion. As a consequence, it was relevant to conclude that for the PWHT nugget, the bands that contained $T_{B}$ precipitates were also susceptible to intergranular corrosion, as were the other types of parallel bands that contained $T_{1}$ precipitates. However, it was assumed that the corrosion potential of the $T_{1}$ precipitates was more cathodic compared to the corrosion potential of the $T_{B}$ particles because $T_{1}$ precipitates contain less copper. Of course, the lithium content of the precipitates probably influences their corrosion potential also. Therefore, the bands containing $T_{1}$ precipitates were assumed to have a corrosion potential that was more cathodic than those containing $T_{B}$ precipitates. A galvanic coupling phenomenon could be considered between the two types of bands; the bands that contained $T_{1}$ precipitates acted as sacrificial anodes and corroded preferentially in the PWHT nugget.

Therefore, the localisation of the corrosion damage in some parallel bands for the PWHT nugget was explained by the precipitation state, which here appeared to be the critical metallurgical parameter. What was most surprising was the presence of $T_{B}$ precipitates in the grain. Indeed, Gable et al. [5] showed that a heat treatment at $150^{\circ} \mathrm{C}$ promoted the nucleation of $T_{1}$ precipitates, while Chen and Bhat [25] observed $T_{B}$ precipitates at higher temperatures. The post-welding heat treatment for the PWHT nugget corresponded only to an ageing at $155^{\circ} \mathrm{C}$. Therefore, a reasonable hypothesis to explain the presence of $T_{B}$ precipitates at such a low temperature in some parallel bands was the influence of the strain induced. Indeed, it was assumed that the strain induced by the welding process was not the same in the two types of parallel bands. Taking into account that the time-temperature-precipitation diagram could be modified if the strain state of the material was considered, for the PWHT nugget, a critical value for the strain could be identified as the value for which $T_{B}$ precipitates could be formed during the ageing at $155^{\circ} \mathrm{C}$. It would then be easy to understand that in some bands where the strain was higher than the limit value, $T_{B}$ precipitates could be observed, while the strain level could be too low in other types of parallel bands for $T_{B}$ precipitates to be formed. Such a hypothesis meant that even if the precipitation state was a critical metallurgical parameter to explain the localisation of the corrosion damage in the PWHT nugget, the "onion rings" morphology was also a key parameter. Indeed, the two types of parallel bands were assumed to be characterised by different strain levels and thus corresponded to a specific precipitation state as shown previously. It was therefore logical that the corroded bands in the PWHT nugget were superimposed with one type of parallel band characterised by a crystallographic orientation i.e., a strain level. Of course, if the precipitation state was the critical metallurgical parameter, the duration of the post-welding heat treatment was also a key factor. NHT nugget samples were therefore submitted to other modified post-welding heat treat- ment consisting in ageing at $155^{\circ} \mathrm{C}$ for duration times equal to 5 , 9 , and $96 \mathrm{~h}$; the duration time corresponding to the PWHT state being $30 \mathrm{~h}$. After these modified post-welding heat treatments, the samples were submitted to a polarisation test in a $0.7 \mathrm{M} \mathrm{NaCl}$ solution with the L-ST plane exposed to the electrolyte. Observations of the samples after the corrosion tests (Fig. 14) showed that the corrosion damage started to be localised after $9 \mathrm{~h}$ of heat treatment (Fig. 14c). For shorter duration times (Fig. 14a and b), the nuggets exhibited intergranular corrosion on their whole surface. On the contrary, for longer duration times, the surface exhibited the beginnings of localisation that was emphasised when the duration of the heat treatment was increased. Therefore, the results showed that for the strain level induced by the welding process in the samples studied, and in particular in some parallel bands, a 9-h ageing treatment at $155^{\circ} \mathrm{C}$ was the minimal heat treatment for $T_{B}$ precipitates to be formed.

\section{Conclusions}

This work focused on the corrosion behaviour of the nugget in an AA 2050 FSW joint. Two metallurgical states were considered, i.e., the as-welded joint called NHT and a joint submitted to a post-welding heat treatment called PWHT. The results showed that the post-welding heat treatment significantly modified the corrosion behaviour of the nugget. For the NHT nugget, a susceptibility to intergranular corrosion was shown while, for the PWHT nugget, both intergranular and intragranular corrosion features were observed. Mechanisms were proposed to explain the susceptibility to corrosion. For both nuggets, the precipitation state was identified as the critical metallurgical parameter. Moreover, results displayed heterogeneities in the corrosion behaviour of the nuggets. First, for both nuggets, galvanic coupling phenomena were observed between the top and bottom of the nuggets, which did not present the same electrochemical behaviour; a relationship between the grain size and the electrochemical behaviour of the nugget was evidenced but it was not possible to conclude since modifications of the grain size imparted other microstructural changes. Then, for the PWHT nugget, another galvanic coupling phenomenon was illustrated between parallel bands called "onion rings". The results showed that two types of bands could be identified by their crystallographic orientations and precipitation state and thus by their electrochemical behaviour. Therefore, the results allowed critical metallurgical parameters to be identified to explain the corrosion behaviour of both the NHT and PWHT nuggets.

\section{Acknowledgments}

This work was financially supported by the ANR MatetPro program (ANR-08-MAPR-0020-05). The authors thank C. Henon (Constellium, Voreppe, France) for the material and P. de Parseval for the EPMA analyses.

\section{References}

[1] W.M. Thomas, E.D. Nicholas, J.C. Needham, M.G. Murch, P. Templesmith, C.J. Dawes, International patent application no. PCT/GB92/02203, 1991.

[2] V. Proton, J. Alexis, E. Andrieu, C. Blanc, J. Delfosse, L. Lacroix, G. Odemer, J. Electrochem. Soc. 158 (2011) C139-C147.

[3] B.P. Huang, Z.Q. Zheng, Scripta Mater. 38 (1998) 357-362.

[4] W.A. Cassada, G.J. Shiflet, E.A. Starke Jr., Metall. Mater. Trans. 22A (1991) 287297.

[5] B.M. Gable, A.W. Zhu, A.A. Csontos, E.A. Starke Jr. J. Light Met. 1 (2001) 1-14.

[6] R.J. Rioja, J. Liu, Metall. Mater. Trans. A 43 (2012) 3325-3337.

[7] A.K. Shukla, W.A. Baeslack, Scripta Mater. 56 (2007) 513-516.

[8] Y.S. Sato, H. Kokawa, M. Enomoto, S. Jogan, Metall. Mater. Trans. A 30 (1999) 2429-2437.

[9] M. Jariyaboon, A.J. Davenport, R. Ambat, B.J. Connolly, S.W. Williams, D.A. Price, Corros. Sci. 49 (2007) 877-909. 
[10] E. Bousquet, Durabilité des assemblages soudés par friction stir Welding (FSW) Corrélation entre microstructure et sensibilité à la corrosion, $\mathrm{PhD}$ thesis, Université Bordeaux 1, 2011.

[11] Ph. Lequeu, R. Muzzolini, J.C. Ehrstrom, F. Bron, R. Maziarz, High-Performance friction stir welded structures using advanced alloys, Aeromat 2006, Seattle Wa, USA, 2006.

[12] M.W. Mahoney, C.G. Rhodes, J.G. Flintoff, R.A. Spurling, W.H. Bingel, Metall. Mater. Trans. A 29 (1998) 1955-1964.

[13] K.V. Jata, S.L. Semiatin, Scripta Mater. 43 (2000) 743-749.

[14] K. Masaki, Y.S. Sato, M. Maeda, H. Kokawa, Scripta Mater. 58 (2008) 355-360

[15] M.A. Sutton, B. Yang, A.P. Reynolds, R. Taylor, Mater. Sci. Eng. A323 (2002) 160-166.

[16] P.S. Pao, E. Lee, C.R. Feng, H.N. Jones, D.W. Moon, Corrosion fatigue in FSW welded Al 2519, in: K.V. Jata, M.W. Mahoney, R.S. Mishra, S.L. Semiatin, T. Lienert (Eds.), Friction Stir Welding and Processing II, TMS, Warrendale, PA, USA, 2003, pp. 113-122.

[17] R.W. Fonda, J.F. Bingert, Metall. Mater. Trans. A 37 (2006) 3593-3604.

[18] K. Kumar, S.V. Kailas, Mater. Sci. Eng. A 485 (2008) 367-374.

[19] K.N. Krishnan, Mater. Sci. Eng. A 327 (2002) 246-251.

[20] G.R. Cui, Z.Y. Ma, S.X. Li, Scripta Mater. 58 (2008) 1082-1085.

[21] N. Birbilis, R.G. Buchheit, J. Electrochem. Soc. 152 (2005) B140-B151.

[22] J.F. Li, Z.Q. Zheng, N. Jiang, S.C. Li, Mater. Corros. 56 (2005) 192-196.

[23] J.F. Li, C.X. Li, Z.W. Peng, W.J. Chen, Z.Q. Zheng, J. Alloys Compd. 460 (2008) 688-693.

[24] H.S. Isaacs, G. Adzic, C.S. Jeffcoate, Corrosion 56 (2000) 971-978.
[25] P.S. Chen, B.N. Bhat, Time-temperature-precipitation behaviour in AI-Li alloy 2195, NASA technical report 211548, 2002.

[26] A. Di Schino, J.M. Kenny, J. Mater. Sci. Lett. 21 (2001) 1631-1634.

[27] K.D. Ralston, D. Fabijanic, N. Birbilis, Electrochim. Acta 56 (2011) 1729-1736.

28] J.A. Schneider, A.C. Nunes, P.S. Chen, G. Steele, J. Mater. Sci. 40 (2005) $4341-$ 4345.

[29] B.W. Davis, The influence of the crystal orientation on the corrosion behavior of aluminum, USNA Trident Scholar project report no. 245, US NAVAL Academy, Anapolis, USA, 1997.

[30] L.J. Korb, Metals Handbook, ASM International Ninth Edition, Corrosion 13, 1987.

[31] P. Niskanen, T.H. Sanders Jr., J.G. Rinker, M. Marek, Corros. Sci. 22 (1982) $283-$ 304.

[32] K.D. Ralston, N. Birbilis, C.H.J. Davies, Scripta Mater. 63 (2010) 1201-1204.

[33] J.G. Brunner, N. Birbilis, K.D. Ralston, S. Virtanen, Corros. Sci. 57 (2012) 209214.

[34] S. Gollapudi, Corros. Sci. 62 (2012) 90-94.

[35] S. Zhao, D.A. Wolfe, T.S. Huang, G.S. Frankel, J. Stat. Planning Inf. 137 (2007) 2405-2412.

[36] T.S. Mahmoud, J. Mechan, Eng. Sci. 222 (2008) 1117.

[37] C. Luo, X. Zhou, G.E. Thompson, A.E. Hughes, Corros. Sci. 61 (2012) 35-44.

[38] S.H. Kim, U. Erb, K.T. Aust, Scripta Mater. 44 (2001) 835-839.

[39] A. Deschamps, F. De Geuser, B. Decreus, B. Malard, in: H. Weiland, A.D. Rollett, W.A. Cassada (Eds.), 13th International Conference on Aluminum Alloys (ICAA13), TMS (The Minerals, Metals \& Materials Society), 2012, pp. 11451154. 